\title{
Breastfeeding self efficacy among pregnant women in Saudi Arabia
}

Reham M. Khresheh, MNEd, PhD, Nagwa M. Ahmed, MSc, PhD.

\begin{abstract}
الأهداف : دراسة العلاقة بين الكفاءة الذاتية للرضاعة الطبيعية لدى الطي

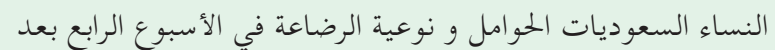

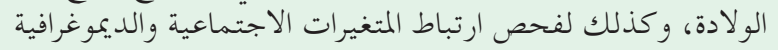

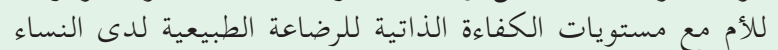

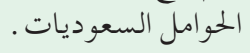

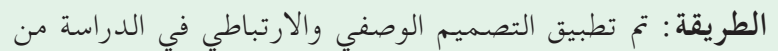

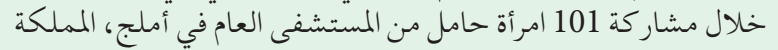

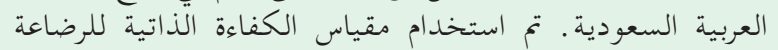

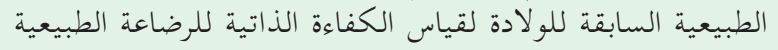

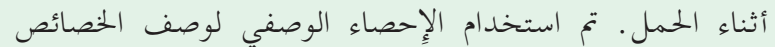

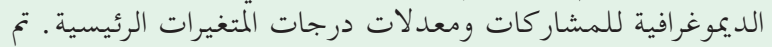

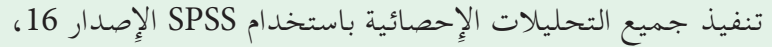
على مستوى دلالة 0.05 0.05

النتائج: كان متوسط درجة الكفاءة الذاتية للرضاعة الطبيعية

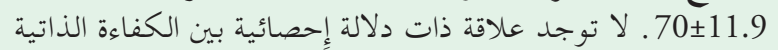

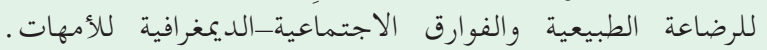

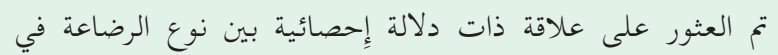

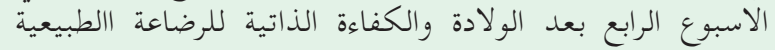

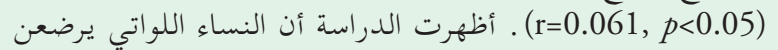

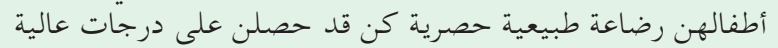

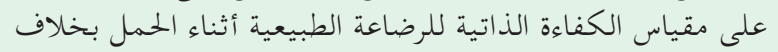

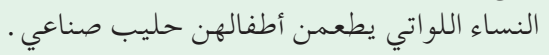

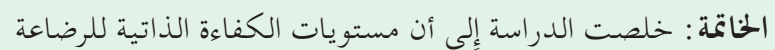

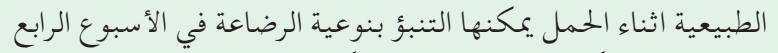

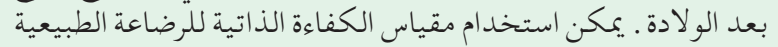

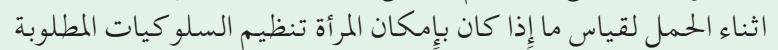

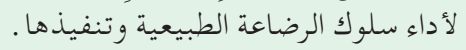

Objectives: To examine the association between prenatal breastfeeding self-efficacy among Saudi pregnant women and type of feeding at 4 weeks post partum, and also to examine the association of maternal socio-demographic variables with the breastfeeding self-efficacy levels of Saudi pregnant women.
Methods: A cross-sectional design has been applied in the study by recruiting 101 pregnant women from the General Hospital, Umluj, Kingdom of Saudi Arabia. The prenatal breastfeeding self-efficacy scale was used to measure self-efficacy for breastfeeding during pregnancy. Descriptive statistics, Chi-square, Pearson correlation coefficient were used for statistical purposes. A $p$-value $\leq 0.05$ was considered significant.

Results: The average breastfeeding self-efficacy score was $70 \pm 11.9$. No significant relationship was existed between breastfeeding self-efficacy and the maternal sociodemographic variables. A significant relationship was found between type of feeding at 4 weeks postpartum and prenatal breastfeeding self-efficacy $(\mathrm{r}=0.061, p<0.05)$. Women who exclusively breastfeed their babies had high scores on prenatal breastfeeding self-efficacy scale than those who mixed feed or bottle feed their infants.

Conclusion: Levels of prenatal breastfeeding selfefficacy among Saudi pregnant women were high and can be predictive of breastfeeding exclusivity at 4 weeks postpartum. The prenatal breastfeeding self-efficacy could be used to measure whether the woman could organize and execute the causes of action needed to perform breastfeeding behavior.

Saudi Med J 2018; Vol. 39 (11): 1116-1122 doi: $10.15537 /$ smj.2018.11.23437

From the Department of Nursing, University College of Umluj, University of Tabuk, Tabuk, Kingdom of Saudi Arabia.

Received 6th August 2018. Accepted 26th September 2018.

Address correspondence and reprint request to: Dr. Reham M. Khresheh, Department of Nursing, University College of Umluj, University of Tabuk, Tabuk, Kingdom of Saudi Arabia. E-mail: reham1966@yahoo.com ORCID ID: orcid.org/0000-0003-4656-3290

Disclosure. This study was funded by University of Tabuk, Tabuk, Kingdom of Saudi Arabia, under research project number S-1437-0020. 
$\mathrm{B}_{\mathrm{d}}^{\mathrm{r}}$ reastfeeding is critical for infant health and development globally. World Health Organization recommended in its charter to breastfeed infants exclusively for the first 6 months. ${ }^{1,2}$ Breastfeeding provides nutritional, immunologic, psychological, social, economic, and environmental benefits to both mother and child. ${ }^{2,3}$ It also accounts for developing stronger bond between mother and baby. ${ }^{4}$ Regardless of such advantages of breastfeeding, exclusive breastfeeding rates are still low in many regions of the world. 5,6 Therefore, there is a need to promote this optimal method of infant feeding to ensure the best possible health outcomes for women and their children.?

Kingdom of Saudi Arabia (KSA) has a population of 27 million, among which $24 \%$ of them live in the Western Region. ${ }^{8}$ Literature review regarding breastfeeding in KSA indicated a progressive decline in the duration of breastfeeding. ${ }^{5,9} \mathrm{Al}$ Juaid et al, ${ }^{9}$ reviewed the literature and predicted factors that accounts for the decline in breastfeeding practice and duration among Saudi population. The results suggested a high breast feeding initiation rates among Saudi women (mostly $>90 \%$ ), the exclusive breastfeeding rates ranged between $0.8-43 \%$, a part from it, the most common feeding method was found to be the mixed feeding, and insufficient breast milk was found to be the real culprit for breastfeeding cessation. ${ }^{9}$ Although breastfeeding initiating rates in KSA are high as compared to the infants consuming formula milk; the number of women, who continued to breastfeed until the recommended duration, is still very low. For instance, the duration of breastfeeding decreased to 8.5 month from 13.4 months, as reported in a study. Several studies have been conducted globally to address the issues of poor breastfeeding outcomes and evaluate strategies for addressing such complications. ${ }^{10}$ Previous studies reported perceived challenges as a reason to stop breastfeeding, rather than, maternal choice. ${ }^{11,12}$ As explained by Bandurảs cognitive social theory, self-efficacy is a cognitive dynamic process that assesses peoples' beliefs and their ability to conduct a health behavior. ${ }^{13}$ Such that, the theory suggests that the behavior of human is self-regulated, namely, their behaviors are being triggered based on their self-efficacy beliefs. They look forward to avoid situations which they believe that they are incapable to solve and look for situations which can be easily solved by them. To this end, breastfeeding was highly affected by the breastfeeding self-efficacy of mothers. ${ }^{14}$ To support this statement, the previous literature reported a significant association between exclusive breastfeeding and breastfeeding self-efficacy. ${ }^{14-16}$ In the early postpartum period, breastfeeding self-efficacy was found to be a strong predictor of breastfeeding intention, and predicting breastfeeding duration. ${ }^{15,17,18}$ The results of the previous studies showed that high levels of breastfeeding self-efficacy among women encouraged them to breast feed their babies exclusively; whereas, poor levels of breastfeeding self-efficacy among women led them to experience postpartum depressive symptoms. ${ }^{19}$

Only few women are capable of meeting the recommended feeding guidelines; however, women with high-levels of self-efficacy tends to continue long-term breastfeeding. ${ }^{15,20}$ Breastfeeding experiences, such as, watching other women breastfeed, encouragement from influential others and influence of one's physiological or affective states tend to play an important role in breastfeeding self-efficacy. ${ }^{10}$ Randomized controlled trials results suggested that professional and lay support can play a significant role to increase breastfeeding duration and exclusivity rates. ${ }^{21}$

Past literature on breastfeeding in KSA further suggested that there are limited studies, which have assessed such issues. Therefore, this study aims to examine the association between prenatal breastfeeding self-efficacy among Saudi women and type of feeding at 4 weeks postpartum, and also to examine the association of maternal socio-demographic variables with the breastfeeding self-efficacy levels of Saudi pregnant women. Results could be helpful to identify characteristics of pregnant women with decreased selfefficacy of breastfeeding to plan strategies for enhancing self-efficacy and encouraging successful breastfeeding.

Methods. The study has employed across-sectional design for collecting data. A convenient sample of 200 pregnant women was recruited from the prenatal care clinic at the General Hospital, Umluj, KSA. Eligible participants were pregnant women, who were able to understand, speak, and read Arabic; and with a singleton fetus. Multiple pregnancy women, who had a contraindication to breastfeeding were excluded from the study. After exclusion, a total of 101 women were selected for conducting the study analysis. Approval to conduct the study was obtained from the Ethical Committee of Tabuk University, KSA. Written consent to participate was also obtained from all participants under ethical approval number: H-01-R-012.

Data collection. Data was collected between June 2016 and June 2017. Pregnant women were approached in the waiting room of prenatal clinic of Umluj Hospital in Tabuk, KSA. The participants completed a self-reported questionnaire after the purpose was explained. The questionnaire included 
3 sections. The first section collected information on sociodemographic characteristics of women including age, level of education, employment status, and economic status. The second section, collected information on the current pregnancy, breastfeeding intention; and previous breastfeeding experience. In the third section, women were asked to fill out the prenatal breastfeeding self-efficacy scale. At 4 weeks postpartum, data on type of feeding (exclusive, mixed, or bottle feeding) were collected by the first researcher through phone interviews with participants.

Instrument. The prenatal breastfeeding self-efficacy scale 20 is a 20 -item, self-report scale that measures self-efficacy for breastfeeding during pregnancy. This scale showed an adequate internal consistency with a Cronbach's alpha of 0.89 . Women responses were made on a 5-point Likert scale, ranging from 1 (not sure) to 5 (completely sure). The overall scores ranged from 20-100. Higher scores indicate greater breastfeeding self-efficacy. This instrument assesses 4 factors, including 7 items related to confidence regarding the skills and demands required for breastfeeding or extracting breast milk, 5 items related to confidence regarding gathering information about how to breastfeed, 4 items related to confidence regarding breastfeeding around people and feeling of embarrassment during breastfeeding, and 2 items related to confidence regarding social pressure when breastfeeding. The remaining 2 items are independent that can assess confidence to discuss the importance of breastfeeding for one year.

Instrument translations. Blind-back translation was used to translate the instrument from English into Arabic to ensure the technical and semantic equivalence. ${ }^{22}$ The translation from English to Arabic was conducted by 2 bilingual experts. Then, back translation of the Arabic version into English was conducted by another 2 external bilingual persons, who had not seen the original English version of the scale. The original and the translated versions were compared; however, no important differences were found between the original English version and the back translated version.

To assess the content validity of the Arabic version, 3 academic experts in the field of maternal and child health nursing and one expert in breastfeeding reviewed the items to determine whether they were understandable and suitable for the culture of KSA. Moreover, 10 pregnant women completed the scale to assess the face validity. Scale items were easily understood by all women $(100 \%)$.

The Cronbach's alpha coefficient for the translated prenatal breastfeeding self-efficacy scale was 0.83 and was not increased in response to the deletion of one or more items. All corrected items-total correlations were positive, and $75 \%$ of the items were above 0.30 . Cronbach's alpha was estimated, when an item was dropped from the scale range from 0.81-0.84. The item mean of the scale was 3.5 (range $=2.2-4.5)$, with a mean item variance 1.5 (range=0.73-2.1). The intra-class correlation coefficient for the translated prenatal breastfeeding self-efficacy scale ranged from 0.77-0.87 with a mean of 0.83 . Factor analysis was performed for the Arabic version of the prenatal breastfeeding self-efficacy scale incorporating a priniciple component extraction method. The factor load of 1.0 was used to determine the nontrivial factors, which produced 4 factors with eigenvalue more than one. All items observed to grouped under sub-scales similar to the original scale. The factor loading items in each sub-scale vary between $0.30-0.79$. The variance explained was $27.9 \%$.

Statistical analysis. Descriptive statistics were used to describe demographic characteristics of participants and mean scores of the major variables. Internal consistency was calculated using Cronbach's alpha. Chi-square (phi test) was used to compare breastfeeding self-efficacy scores of women according to the sociodemographic characteristics. Pearson's correlation was used to describe the relationship between breast feeding self-efficacy and type of feeding at 4 weeks. All statistical analysis was performed using SPSS version 16 (SPSS Inc., Chicago. IL, USA), at the significance level of $p \leq 0.05$.

Results. Among the total of 200 pregnant women, only $101(50.5 \%)$ agreed to take part and completed the questionnaire. Table 1 has shown the sociodemographic characteristics of the participant women. The mean age of the women was 28 years (range from 20-45); all of them were married; and $66.3 \%$ were multiparous. One-third of the pregnant women $(n=34 ; 33.7 \%)$ had worked in professional settings; $75 \%$ were university graduates; $42.5 \%$ were in the second trimester of the pregnancy; 96\% planned for breastfeeding their newborn; and $59 \%$ had past experience of breastfeeding. Almost all (96\%) husbands were working professionally; and 57\% of them were university graduates. Most $(71 \%)$ of the sample reported a monthly income of SR 5000-10,000 (middle-income status), with the remaining women reporting lower than $5000 \mathrm{SR}(\mathrm{n}=25 ; 24.8 \%)$ and more than 10,000 SR $(n=4 ; 4 \%)$. The vast majority $(n=97$; $96 \%$ ) of women in the sample reported that they intended to breastfeed their babies. Sixty women (61\%) had past experience of breastfeeding. 
Table 1 - The sociodemographic characteristics of the participant women.

\begin{tabular}{|c|c|}
\hline Characteristics & n $\quad(\%)$ \\
\hline \multicolumn{2}{|c|}{ Age (range 20-45) (mean $=28$ years) } \\
\hline $\begin{array}{l}\text { Less than } 30 \\
30-35 \\
\text { More than } 35\end{array}$ & $\begin{array}{r}65(64.3) \\
35(34.7) \\
1 \quad(1.0)\end{array}$ \\
\hline \multicolumn{2}{|l|}{ Education level } \\
\hline $\begin{array}{l}\text { Primary } \\
\text { Secondary } \\
\text { University } \\
\text { Other }\end{array}$ & $\begin{array}{cr}8 & (8.0) \\
16 & (15.8) \\
76 & (75.2) \\
1 & (1.0)\end{array}$ \\
\hline \multicolumn{2}{|l|}{ Work status } \\
\hline $\begin{array}{l}\text { Employed } \\
\text { Unemployed }\end{array}$ & $\begin{array}{l}34(33.7) \\
67(66.3)\end{array}$ \\
\hline \multicolumn{2}{|c|}{ Monthly salary $(3000-14,000 S R)$ mean $=7300 S R$} \\
\hline $\begin{array}{l}\text { Less than } 5000 \\
5000-10,000 \\
\text { More than } 10,000\end{array}$ & $\begin{array}{r}25(24.8) \\
72(71.2) \\
4 \quad(4.0)\end{array}$ \\
\hline \multicolumn{2}{|c|}{ No. of previous pregnancies } \\
\hline $\begin{array}{l}0 \\
1 \\
2 \\
3 \text { and more }\end{array}$ & $\begin{array}{l}34(33.6) \\
14(13.9) \\
39(38.6) \\
14(13.9)\end{array}$ \\
\hline \multicolumn{2}{|c|}{ Gestational age of current pregnancy (months) } \\
\hline $\begin{array}{l}\text { First trimester } \\
\text { Second trimester } \\
\text { Third trimester }\end{array}$ & $\begin{array}{l}19(19.1) \\
42(42.5) \\
38(38.4)\end{array}$ \\
\hline \multicolumn{2}{|l|}{ Plan for breastfeeding } \\
\hline $\begin{array}{l}\text { Yes } \\
\text { No }\end{array}$ & $\begin{array}{r}97(96.0) \\
4 \quad(4.0)\end{array}$ \\
\hline \multicolumn{2}{|c|}{ Past experience of breastfeeding } \\
\hline $\begin{array}{l}\text { Yes } \\
\text { No }\end{array}$ & $\begin{array}{l}60(59.4) \\
41(40.6)\end{array}$ \\
\hline
\end{tabular}

The average breastfeeding self-efficacy score was $70 \pm 11.9$, with the scores ranging from 34-96. The results showed that no significant relationship was existed between breastfeeding self-efficacy and the sociodemographic characteristics of the sample, previous experience, or intention to breastfeed (Table 2). Results further showed that women in the age group less than 30 years, university graduates, who do not have jobs, with monthly income of 5000-10,000 SR, who planned for breastfeeding, and had previous breastfeeding experience had higher scores on the breastfeeding selfefficacy scale as compared to the women in the other categories. Although $96 \%$ of participants intended to breastfeed; only $68 \%(n=69)$ of participants were doing so at 4 weeks postpartum. Forty-six (45.6\%) of participant were exclusively breastfeed their babies; 23 (22.8\%) were mixed feeding; and $32(31.6 \%)$ of women were bottle feeding. A significant relationship was found between type of feeding at 4 weeks postpartum and prenatal breastfeeding self-efficacy $(\mathrm{r}=0.61, p<0.05)$. Results showed that women; who exclusively breastfeed their babies; had high scores on prenatal breastfeedings self-efficacy scale than those who mixed feed or bottle feed their babies (Table 2).

Discussion. The study has aimed to examine the relationship between breastfeeding self-efficacy and maternal demographic variables, using the Arabic version of the prenatal breastfeeding self-efficacy scale. The findings found that prenatal breastfeeding self-efficacy scale is a reliable measure of breastfeeding self-efficacy among pregnant women in KSA. Findings are consistent with outcomes of previous studies with various samples. ${ }^{20,23,24}$ The value of Cronbach's Alpha of the Arabic scale (0.83) was found to be within the recommendations for established instrument ${ }^{17}$ and is also comparable with the original prenatal breastfeeding self-efficacy scale Cronbach's alpha of 0.8920 . The overall mean prenatal breastfeeding self-efficacy scores for the 101 Saudi pregnant women were relatively high, considering that the mean score out of a possible 100 was 70. It suggested that pregnant women in KSA were confident in their ability to breastfeed their babies.

It was found that maternal sociodemographic characteristics have significant influence on breastfeeding behavior; however, improvement was observed with past breastfeeding experience and better education. ${ }^{25,26}$ No significant relationship was found between prenatal breastfeeding self-efficacy and sociodemographic characteristics of the participants in this study. These findings are consistent with previous research and acknowledged the uniqueness of prenatal breastfeeding self-efficacy tool in identifying prenatally women, who may benefit from additional support to improve breastfeeding outcomes. ${ }^{20,23-25}$

Findings of this study show that the majority of the women; who planned to breastfeed; breastfed their babies at 4 weeks postpartum. This result is consistent with findings of previous studies showing that most women took decisions regarding the methods of infant feeding before the end of pregnancy. Those women who did not show any intention to breastfeed had low breastfeeding self-efficacy as compared to the women who intended to breastfeed. These results were found to be consistent with the findings of previous studies showing women who did not show any intention to breastfeed possessed less confidence regarding breastfeeding self-efficacy as compared to the women who intended to breastfeed. The predictor, breastfeeding intent, is modifiable; that is why, it targets breastfeeding self-efficacy in the prenatal period. ${ }^{20,24}$ 
Table 2 - The relationship between socio-demographic variables and prenatal breastfeeding self-efficacy.

\begin{tabular}{|c|c|c|c|c|c|}
\hline \multirow{2}{*}{\multicolumn{6}{|c|}{$\begin{array}{l}\text { Variables } \\
\text { Age (range20-45) (mean }=28 y r s)\end{array}$}} \\
\hline & & & & & \\
\hline $\begin{array}{l}<30 \\
30-35 \\
>35\end{array}$ & $\begin{array}{lr}4 & (4.0) \\
2 & (2.0) \\
0 & (0)\end{array}$ & $\begin{array}{r}21(21.2) \\
20(20.2) \\
1(1.0)\end{array}$ & $\begin{array}{rr}38 & (38.4) \\
15 & (15.2) \\
& 0(0)\end{array}$ & $\begin{array}{rr}63 & (63.6) \\
37 & (37.4) \\
1 & (1.0)\end{array}$ & 0.095 \\
\hline \multicolumn{6}{|l|}{ Education level (woman) } \\
\hline $\begin{array}{l}\text { Primary } \\
\text { Medi } \\
\text { Secondary } \\
\text { University } \\
\text { Other }\end{array}$ & $\begin{array}{lr}0 & (0) \\
0 & (0) \\
1 & (1.0) \\
3 & (3.0) \\
0 & (0)\end{array}$ & $\begin{array}{r}2(2.0) \\
3(3.0) \\
8(8.1) \\
29(29.3) \\
0(0.0)\end{array}$ & $\begin{array}{rr}2 & (2.0) \\
1 & (1.0) \\
7 & (7.1) \\
42 & (42.4) \\
& 1(1.0)\end{array}$ & $\begin{array}{rr}4 & (4.0) \\
4 & (4.0) \\
16 & (16.2) \\
74 & (74.7) \\
1 & (1.0)\end{array}$ & 0.867 \\
\hline \multicolumn{6}{|l|}{ Education level (husband) } \\
\hline $\begin{array}{l}\text { Primary } \\
\text { Secondary } \\
\text { University } \\
\text { Other }\end{array}$ & $\begin{array}{rr}0 & (0) \\
2 & (0) \\
2 & (2.0) \\
0 & (0)\end{array}$ & $\begin{array}{r}2(2.0) \\
16(16.2) \\
24(24.2) \\
0(0)\end{array}$ & $\begin{array}{rr}2 & (2.0) \\
18 & (18.2) \\
30 & (30.3) \\
3 & (3.0)\end{array}$ & $\begin{array}{rr}4 & (4.0) \\
36 & (36.4) \\
56 & (56.6) \\
3 & (3.0)\end{array}$ & 0.785 \\
\hline \multicolumn{6}{|l|}{ Work status (woman) } \\
\hline $\begin{array}{l}\text { Employed } \\
\text { Unemployed }\end{array}$ & $\begin{array}{lr}0 & (0) \\
4 & (4.0)\end{array}$ & $\begin{array}{l}16(16.2) \\
26(26.3)\end{array}$ & $\begin{array}{ll}16 & (16.2) \\
37 & (37.4)\end{array}$ & $\begin{array}{l}32(32.3) \\
67(67.7)\end{array}$ & 0.264 \\
\hline \multicolumn{6}{|l|}{ Workstatus (husband) } \\
\hline $\begin{array}{l}\text { Employed } \\
\text { Unemployed }\end{array}$ & $\begin{array}{rr}4 & (4.0) \\
0 & (0)\end{array}$ & $\begin{array}{r}38(38.4) \\
4(4.0)\end{array}$ & $\begin{array}{rr}53 & (53.5) \\
0 & (0.0)\end{array}$ & $\begin{array}{r}95(96.0) \\
4 \quad(4.0)\end{array}$ & 0.059 \\
\hline \multicolumn{6}{|c|}{ Monthly salary (3000-14,000SR) } \\
\hline $\begin{array}{l}\text { Less than } 5000 \\
5000-10,000 \\
\text { More than 10,000 }\end{array}$ & $\begin{array}{lr}1 & (1.0) \\
3 & (3.0) \\
0 & (0)\end{array}$ & $\begin{array}{r}9(9.1 .0) \\
31(31.3) \\
2(2.0)\end{array}$ & $\begin{array}{rr}15 & (15.2) \\
36 & (36.4) \\
2 & (2.0)\end{array}$ & $\begin{array}{rr}25 & (25.3) \\
70 & (70.7) \\
4 & (4.0)\end{array}$ & 0.950 \\
\hline \multicolumn{6}{|l|}{ No. of previous pregnancies } \\
\hline $\begin{array}{l}0 \\
1 \\
2 \\
\geq 3\end{array}$ & $\begin{array}{rr}3 & (3.0) \\
0 & (0) \\
1 & (1.0) \\
0 & (0)\end{array}$ & $\begin{array}{r}15(15.2) \\
4(4.0) \\
12(12.1) \\
11(11.1)\end{array}$ & $\begin{array}{rr}16 & (16.2) \\
8 & (8.1) \\
20 & (20.2) \\
9 & (9.1)\end{array}$ & $\begin{array}{ll}34 & (34.3) \\
12 & (12.1) \\
33 & (33.3) \\
20 & (20.2)\end{array}$ & 0.349 \\
\hline \multicolumn{6}{|c|}{ Gestational age of current pregnancy (months) } \\
\hline $\begin{array}{l}\text { First trimester } \\
\text { Second trimester } \\
\text { Third trimester }\end{array}$ & $\begin{array}{ll}2 & (2.1) \\
1 & (1.0) \\
1 & (1.0)\end{array}$ & $\begin{array}{r}9(9.3) \\
15(15.5) \\
17(17.6)\end{array}$ & $\begin{array}{rr}8 & (8.2) \\
26 & (26.8) \\
18 & (18.5)\end{array}$ & $\begin{array}{ll}19 & (19.6) \\
42 & (43.3) \\
36 & (37.1)\end{array}$ & 0.433 \\
\hline \multicolumn{6}{|l|}{ Breastfeeding intention } \\
\hline $\begin{array}{l}\text { Yes } \\
\text { No }\end{array}$ & $\begin{array}{ll}6 & (4.1) \\
0 & (0.0)\end{array}$ & $\begin{array}{r}38(38.4) \\
4(4.0)\end{array}$ & $\begin{array}{rr}53 & (53.5) \\
0 & (0.0)\end{array}$ & $\begin{array}{rr}97 & (96.0) \\
4 & (4.0)\end{array}$ & 0.059 \\
\hline \multicolumn{6}{|c|}{ Past experience of breastfeeding } \\
\hline $\begin{array}{l}\text { Yes } \\
\text { No }\end{array}$ & $\begin{array}{ll}1 & (1.0) \\
3 & (3.0)\end{array}$ & $\begin{array}{l}25(25.3) \\
17(17.2)\end{array}$ & $\begin{array}{ll}34 & (34.3) \\
19 & (19.2)\end{array}$ & $\begin{array}{ll}60 & (60.6) \\
39 & (39.4)\end{array}$ & 0.298 \\
\hline \multicolumn{6}{|c|}{ Breastfeeding outcomes at 4 weeks postpartum } \\
\hline $\begin{array}{l}\text { Exclusive breastfeeding } \\
\text { Mixed feeding } \\
\text { Bottle feeding }\end{array}$ & $\begin{array}{rr}0 & (0.0) \\
2 & (2.0) \\
16 & (15.8)\end{array}$ & $\begin{array}{r}2(2.0) \\
10(9.9) \\
16(15.8)\end{array}$ & $\begin{array}{rr}44 & (43.6) \\
11 & (10.9) \\
0 & (0.0)\end{array}$ & $\begin{array}{ll}46 & (45.6) \\
23 & (22.8) \\
32 & (31.6)\end{array}$ & $0.049^{*}$ \\
\hline
\end{tabular}

Several interventions were developed targeting breastfeeding self-efficacy to improve breastfeeding outcomes among women. In the same context, a study investigated the impact of self-efficacy intervention on breastfeeding self-efficacy and exclusive breastfeeding. The results showed that breastfeeding self-efficacy and exclusive breastfeeding can be improved through interventions at 4 weeks postpartum. ${ }^{27}$ Moreover, infant feeding practices are likely to be optimized earlier, as breastfeeding self-efficacy interventions are being implemented within the hospitals. Another study predicted a high mean score among mothers who exclusively breastfeed their infants as compared to those, who did not. Early breastfeeding discontinuation (exclusive breastfeeding) is observed among the women with low breastfeeding self-efficacy. ${ }^{27}$ 
The study has a small number of limitations. First, the study was conducted in urban public hospitals within western KSA, and the use of convenient sample limited the generalizability of the results. The other limitation of this study is the unavailability of the data regarding women who initiated breastfeeding. Despite these limitations, the findings suggested that the Arabic prenatal breastfeeding self-efficacy scale may be a reliable and valid measure of breastfeeding self-efficacy among pregnant women and be predictive of breastfeeding exclusivity.

In conclusion, this study supported previous literatures that recognize breastfeeding self-efficacy as an important variable influencing breastfeeding outcomes. Health-care professionals in KSA can use the Arabic prenatal breastfeeding self-efficacy scale to identify pregnant women with lower breastfeeding self-efficacy and implement individualized strategies or additional support to enhance confidence in breastfeeding. Prenatal breastfeeding education and support may be the most suitable strategies to increase breastfeeding self-efficacy among pregnant women.

We recommend conducting further research with pregnant women to assess breastfeeding behaviors and perception to the suggested strategies and to evaluate the effectiveness of various interventions.

Acknowledgment. Authors would like to thank all the associated personnel in any reference that contributed in/for the purpose of this research. Authors would like to thank Newton Mentors for English language editing.

\section{References}

1. World Health Organization. Exclusive breastfeeding for optimal growth, development and health of infants [Internet]. Geneva: WHO; 2018 [Accessed 12 September 2018]. Available from: http://www.who.int/elena/titles/ exclusive_breastfeeding/en/

2. World Health Organization. Long-term effects of breastfeeding: a systematic review. Geneva: WHO; 2013.

3. World Health Organization. Short-term effects of breastfeeding. A systematic review on the benefits of breastfeeding on diarrhoea and pneumonia mortality. Geneva: WHO; 2013.

4. Dieterich CM, Felice JP, O'Sullivan E, Rasmussen KM. Breastfeeding and health outcomes for the mother-infant dyad. Pediatr Clin North Am 2013; 60: 31-48.

5. Alzaheb RA. Factors Influencing Exclusive Breastfeeding in Tabuk, Saudi Arabia. Clin Med Insights Pediatr 2017; 11: 1179556517698136.
6. Bisi-Onyemaechi AI, Chikani UN, Ubesie AC, Chime PC, Mbanefo NR. Factors associated with low rate of exclusive breastfeeding among mothers in Enugu, Nigeria. Int J Res Med Sci 2017; 5: 3776-3781.

7. Branca F, Piwoz E, Schultink W, Sullivan LM. Nutrition and health in women, children, and adolescent girls. BMJ 2015; 351: h4173.

8. Central Department of Statistics and Information. Annual statistical book. Riyadh (KSA): Central Department of Statistics and Information; 2014.

9. Al Juaid DA, Binns CW, Giglia RC. Breastfeeding in Saudi Arabia: a review. Int Breastfeed J 2014; 9: 1.

10. Otsuka K, Taguri M, Dennis CL, Wakutani K, Awano $M$, Yamaguchi T, et al. Effectiveness of a breastfeeding self-efficacy intervention: do hospital practices make a difference? Matern Child Health J 2014; 18: 296-306.

11. Eidman CK. Enhancing breast-feeding self-efficacy through prenatal education. [Dissertations]. Saint Paul, Minnesota: St. Catherine University; 2011.

12. Robert E, Coppieters Y, Swennen B, Dramaix M. The Reasons for Early Weaning, Perceived Insufficient Breast Milk, and Maternal Dissatisfaction: Comparative Studies in Two Belgian Regions. Int Sch Res Notices 2014; 2014: 678564.

13. Bandura A. Self-efficacy: toward a unifying theory of behavioral change. Psychol Rev 1977; 84: 191-215.

14. Tokat M, Okumus $\mathrm{H}$. The effect of antenatal training on breastfeeding self-efficacy perception and breastfeeding. J Nurs Educ 2013; 10: 21-29.

15. Shahbar A. Factors associated with breastfeeding in Western of Saudi Arabia [dissertations], New Zealand: Massey University Palmerston North, Massey University; 2014.

16. Baysal H, Turkoglu N, Kucukoglu S. Comparion of perception of breastfeeding selfefficacy of mothers with healthy and sick children. $J$ Dr Behcet Uz Child Hosp 2014; 4: 31-36.

17. Tuthill EL, McGrath JM, Graber M, Cusson RM, Young SL. Breastfeeding Self-efficacy: A Critical Review of Available Instruments. J Hum Lact 2016; 32: 35-45.

18. Labbok MH. Breastfeeding: population-based perspectives. Pediatr Clin North Am 2013; 60: 11-30.

19. Zubaran C, Foresti K. The correlation between breastfeeding self-efficacy and maternal postpartum depression in southern Brazil. Sex Reprod Healthc 2013; 4: $9-15$

20. Wells KJ, Thompson NJ, Kloeblen-Tarver AS. Development and psychometric testing of the prenatal breast-feeding self-efficacy scale. Am J Health Behav 2006; 30: 177-187.

21. McFadden A, Gavine A, Renfrew MJ, Wade A, Buchanan P, Taylor JL, et al. Support for healthy breastfeeding mothers with healthy term babies. Cochrane Database Syst Rev 2017; 2: CD001141. 
22. Abubakar A, Dimitrova R, Adams B, Jordanov V, Stefenel D. Procedures for translating and evaluating equivalence of questionnaires for use in cross-cultural studies. Bulletin of the Transilvania University of Braşov 2013; 6: 79-85.

23. Piñeiro-Albero RM, Ramos-Pichardo JD, Oliver-Roig A, Velandrino-Nicolás A, Richart-Martínez M, Garcíade-León-González R, et al. The Spanish version of the prenatal breast-feeding self-efficacy scale: reliability and validity assessment. Int J Nurs Stud 2013; 50: 1385-1390.

24. Aydin A, Pasinlioglu T. Reliability and Validity of a Turkish version of the Prenatal Breastfeeding SelfEfficacy Scale. Midwifery 2018; 64: 11-16.
25. Nursan C, Dilek K, Sevin A. Breastfeeding Self-efficacy of Mothers and the Affecting Factors. Aquichan 2014; 14: 327-335.

26. Acharya P, Khanal V. The effect of mother's educational status on early initiation of breastfeeding: further analysis of three consecutive Nepal Demographic and Health Surveys. BMC Public Health 2015; 15: 1069.

27. Farzaneh P, Pakseresht S, Khalesi ZB, E.K. L. Factors Associated with Breastfeeding Self-Efficacy of Mothers Within 6 Weeks of Delivery. J Holist Nurs Mid 2017; 27: $27-34$. 